\title{
Article \\ Orally Administered Activated Charcoal as a Medical Countermeasure for Acute Radiation Syndrome in Rats
}

\author{
Elisaveta Snezhkova ${ }^{1, *}$, Natalia Rodionova ${ }^{2}$, Dennis Bilko ${ }^{3}$, Joaquin Silvestre-Albero ${ }^{4}\left(\mathbb{D}\right.$, Alexey Sydorenko ${ }^{1}$, \\ Olga Yurchenko ${ }^{1}$, Marharyta Pakharenko ${ }^{3}$, Mo Alavijeh ${ }^{5}$, Kvitoslava Bardakhivska ${ }^{1}$, Natalia Riabchenko ${ }^{2}$ \\ and Vladimir Nikolaev ${ }^{1}$
}

check for updates

Citation: Snezhkova, E.; Rodionova, N.; Bilko, D.; Silvestre-Albero, J.; Sydorenko, A.; Yurchenko, O.; Pakharenko, M.; Alavijeh, M.; Bardakhivska, K.; Riabchenko, N.; et al. Orally Administered Activated Charcoal as a Medical

Countermeasure for Acute Radiation Syndrome in Rats. Appl. Sci. 2021, 11, 3174. https://doi.org/10.3390/ app11073174

Academic Editor: Nagendra Kumar Kaushik

Received: 7 February 2021

Accepted: 24 March 2021

Published: 2 April 2021

Publisher's Note: MDPI stays neutral with regard to jurisdictional claims in published maps and institutional affiliations.

Copyright: (c) 2021 by the authors. Licensee MDPI, Basel, Switzerland. This article is an open access article distributed under the terms and conditions of the Creative Commons Attribution (CC BY) license (https:/ / creativecommons.org/licenses/by/ $4.0 /)$.
1 Department of Means \& Methods of Adsorptive Therapy, R. E. Kavetsky Institute of Experimental Pathology, Oncology and Radiobiology, National Academy of Sciences of Ukraine, 03022 Kyiv, Ukraine; lexasidua@gmail.com (A.S.); oyurchenko2008@ukr.net (O.Y.); kvitab@yahoo.com (K.B.); nikolvlady@gmail.com (V.N.)

2 Department of Radiobiology and Radioecology, Institute for Nuclear Research of National Academy of Sciences of Ukraine, 02000 Kyiv, Ukraine; rodionovanatala@gmail.com (N.R.); nryabchenko@ukr.net (N.R.)

3 Center of Molecular and Cell Research, National University of Kyiv-Mohyla Academy, 04070 Kyiv, Ukraine; comraduk@yahoo.co.uk (D.B.); margaret.pakharenko@gmail.com (M.P.)

4 Laboratorio de Materiales Avanzados, Departamento de Química Inorgánica-Instituto Universitario de Materiales, Universidad de Alicante, E-03690 San Vicente del Raspeig, Spain; joaquin.silvestre@ua.es

5 Pharmidex Pharmaceutical Services Ltd., London EC2V 8AU, UK; mo.alavijeh@pharmidex.com

* Correspondence: lisasne@hotmail.com; Tel.: +380-953124221; Fax: +380-442579055

Featured Application: High porosity activated charcoal can be administered per orally for mitigation of radiation-induced intoxication and intoxication related to different pathological states.

Abstract: Activated charcoal (AC) can be taken orally as enterosorbent for treatment of pathological states related to exogenous and endogenous intoxications. Synthesized granulated AC with a highly developed active surface $\left(\mathrm{S}_{\mathrm{BET}} \sim 2700 \mathrm{~m}^{2} / \mathrm{g}\right.$ ) was used as a medical countermeasure (MCM) to acute radiation sickness (ARS) in rats after total body X-ray irradiation. AC demonstrates positive results in ARS treatment, as expressed in, (i) a decrease in body weight loss, (ii) a protection of bone marrow (BM) cells colony formation capacity, (iii) a reduction of BM chromosomal aberrations and small intestine and spleen tissue damage, (iv) an amelioration of white blood cell count, and (v) a mitigation of superoxide ion generation rate in the liver. AC oral prescription seems to be perspective modality of ARS treatment.

Keywords: activated charcoal; enterosorbent; acute radiation sickness; rats

\section{Introduction}

Threats of terrorist attacks, expanding nuclear industry, widespread utilization of ionizing radiation in many technologies are potentially exposing the world population to ongoing and new radiation threats.

Therefore, there is an urgent need for developing new Acute Radiation Syndrome (ARS) prevention and treatment strategies. Currently, USA Food and Drug Administration (FDA) approved colony-stimulating factors such as Neupogen, Neulasta, Leukine and thrombopoietin receptor agonist NPLATE to treat those who have received high doses of radiation [1]. These drugs, used also in cancer patients receiving myelosuppressive chemotherapy, accelerate the process of creating white blood cell, boost platelets (NPLATE) and reduce the time that the patient is vulnerable to infection and blood coagulation disorders.

A good medical countermeasure (MCM) for radiation exposure should be easy to handle, safe, stable (under extreme conditions), cheap, deployable and must meet the medical need for rapid therapeutic support including non-radiation medicine [2]. Activated 
charcoal (AC) for medical use from this point of view seems to be ideal MCM. AC successfully increased animals' survival from $3.2 \%$ in control group to $68.1 \%$ when administered during $24 \mathrm{~h}$ after irradiation in experiment for hemoperfusion treatment of dogs irradiated with lethal doses of X-ray [3]. Oral administration of AC alone (or in combination with granulocyte colony-stimulating factor in pre-clinical and clinical trials) after Irradiation or anticancer chemotherapy reduced intoxication, prevented and treated leukopenia [4].

The National Security Hospital after the Chernobyl disaster reported 10 years' experience in hemo- and enterosorption application of $\mathrm{AC}$ in the effective treatment of post-irradiation injuries in patients [5]. AC showed high adsorption capacity towards toxic substances that appear in different pathological states, particularly in ARS. AC with high adsorptive capacity effectively removes cytokines of different size (IL-6 and IL-8), protein-bound molecules (hippuric acid and indoxyl sulfate) and middle-sized molecules, such as $\beta$-2-microglobulin [6]. AC mitigates manifestation of oxidative stress, contributes to restoration of natural detoxification potential of organism through deliganding serum proteins (in particular-albumin) from endogenous metabolites and toxins [7].

ARS is the result of direct and indirect mechanisms of ionizing radiation action on cells. Reactive oxygen species, proinflammatory cytokines/chemokines and induction of gene expression provoke oxidative damage, inflammation, innate immune response leading to cell death and damage [8,9]. These indirect damage effects of ionizing radiation can probably be reduced by AC, that removes cytokines, protein-bound substances, middlesized molecules and endogenous metabolites from biological fluids. Radiation leads to multiple organ dysfunction syndrome and life-threatening multiple organ failure [9]. It provokes severe damage in gastrointestinal system [10] and brain [11]. Bone marrow or hematopoietic syndrome is the most classically recognized ARS. Relatively low levels of exposure can result in bone marrow failure, potentially lethal hemorrhage or infections [12]. In the present work, we aimed to investigate the potential of the newly developed orally administered highly activated charcoal as a possible ARS medical countermeasure. Effect of AC on reducing weight loss, ionizing radiation-induced injury in hematopoietic tissue, small intestine, spleen, thymus and superoxide ion generation in the brain and liver was evaluated in rats after total body $\mathrm{X}$-ray irradiation in sublethal dose.

\section{Materials and Methods}

\subsection{Synthesis and Characterization of Activated Carbon for Enterosorption}

2.1.1. Synthesis of AC

Activated carbon beads with particle diameter of $0.1 \mathrm{~mm} \leq \mathrm{d} \leq 0.25 \mathrm{~mm}$ and bulk density $0.12 \mathrm{~g} / \mathrm{cc}$ have been prepared in multiple steps, comprising:

(1) Synthesis of the beads of 2-methyl-5-vinylpiridine copolymer with styrene divinyl benzene (Taiyan Lanlang Technology Industry Corp., Taiyan, China);

(2) Carbonization of these beads at $400{ }^{\circ} \mathrm{C}$ in the nitrogen atmosphere in rotary kiln with rotation speed of $0.5 \mathrm{rpm}$;

(3) "Consolidation" in nitrogen atmosphere at $800{ }^{\circ} \mathrm{C}$;

(4) First activation of the carbonizate by steam at $860^{\circ} \mathrm{C}$ in rotary kiln up to bulk density of $0.28 \mathrm{~g} / \mathrm{cc}$;

(5) Second activation in fluidized bed in laboratory kiln by steam up to bulk density of $0.12 \mathrm{~g} / \mathrm{cc}$;

(6) Sieving.

\subsubsection{Surface and Porosity Parameters}

Porosity parameters of AC have been determined by standard methods: nitrogen adsorption [13] at cryogenic temperatures. N2 adsorption/desorption isotherms were performed in a home-made manometry device designed and constructed by the LMA group. Prior to the adsorption measurement, sample was outgassed under ultra-high vacuum at $250{ }^{\circ} \mathrm{C}$ overnight. Apparent surface area was obtained after application of the 
BET (Brunauer, Emmett and Teller) equation to the nitrogen adsorption data, and total pore volume was deduced from the amount adsorbed at $\mathrm{p} / \mathrm{p} 0=0.97$.

\subsection{Assessment of AC Enterosorbent Efficacy in Animal Model with ARS}

\subsubsection{Animal Model}

Two weeks before the start of the study (approved by IEPOR Committee on Bioethics, protocol No 4 dated 16 April 2015), thirty male Wistar rats (six weeks old) with body weight $\cong 140 \mathrm{~g}$ were individually housed for the purpose of determining oat porridge consumption levels. All animals had ad libitum access to standard food and water in accordance with the provisions of the European Convention for the Protection of Vertebrate Animals Used for Experimental and Other Scientific Purposes (Strasbourg, 1986). During the adaptation period, animals were fed additionally to standard food with thick oat porridge from rolled oats flakes (cooked in $1 \mathrm{~L}$ of water with 1 teaspoon of unrefined sunflower oil, after good thickening and solidification, $50 \mathrm{~g}$ of carrot and $50 \mathrm{~g}$ of apple finely grated were added). Animals were randomly allocated into 3 groups: 1 -irradiated rats-Ir. control $(n=10)$; 2 -irradiated rats receiving AC enterosorbent - Ir $+A C(n=10)$; 3 -healthy rats- $-H$. control $(\mathrm{n}=10)$. The daily dose of $\mathrm{AC}$ was $1.2 \mathrm{~g}$ per $1 \mathrm{~kg}$ of rat's body weight, mixed in a small amount (teaspoon) of oat porridge. This dose consumption was controlled visually because each rat was in separate cage and the preliminary withdrawal for $2-3 \mathrm{~h}$ of habitual food ensured $\mathrm{AC}$ daily dose consumption. $\mathrm{AC}$ was fed to rats for 3 days before irradiation, on irradiation day and for 9 days post- irradiation. Both control groups received only oat porridge by the same scheme as group 2 . Half the animals of each group ( 5 rats) were sacrificed under general chloroform anesthesia for blood and organ collection on the 1st day post-irradiation (post-Ir), second half (5 rats)—on the 9th day post-Ir.

\subsubsection{Irradiation}

Ionizing radiation was delivered to 8-week-old rats weighing $196 \mathrm{~g} \pm 20$ (prior to irradiation), using an X-ray RUM-17 irradiator with a working current of $10 \mathrm{~mA}, 0.5 \mathrm{~mm}$ $\mathrm{Cu}$ filter, $30 \mathrm{~cm}$-target distance in rotating box $(24 \times 15 \mathrm{~cm})$ for 4 rats during $11 \mathrm{~min}$. In order to immobilize the animals, anesthesia was induced by intraperitoneal administration of pentobarbital $0.5 \%$ (10 mL/kg body weight), $12 \mathrm{~min}$ prior to irradiation in order to ensure the loss of reflex activity. Control group animals underwent the same procedure, excluding irradiation. The absorbed sublethal dosage per rat was $6 \mathrm{~Gy}(54.5 \mathrm{cGy} / \mathrm{min}$ during $11 \mathrm{~min}$ ), which was applied in the morning between 10-11 a.m.

\subsubsection{Blood and Bone Marrow Cell Count}

Terminal blood samples were obtained via cardiac puncture and blood cell counts were performed on particle counter PCE-210, Erma Inc., Tokyo, Japan. Bone marrow cell suspension and smears were prepared from rat femurs. The femur was dissected, cleaned, and the ends of the bones were chipped. Bone marrow was extracted from the femur into $1 \mathrm{~mL}$ solution of $3 \%$ acetic acid containing $50 \mathrm{U}$ heparin, and the bone marrow canal was thoroughly rewashed with the same solution. At least 1000 cells per rat were counted and Pappenheim staining smears were analyzed for all 30 rats. The smears were interpreted without knowledge of previous treatment.

\subsubsection{Chromosome Aberration Test}

Preparation of metaphase chromosome spreads of bone marrow cells was done accordingly [14] with some modifications. The obtained slides were coded and scored blind using a light microscope under $1000 \times$ magnification. Not less than 100 metaphase spreads per animal were analyzed for chromosome and chromatid type rearrangements.

\subsubsection{Functional Activity of Bone Marrow Cells}

Femoral bone marrow cells of rats under sterile conditions were removed and cultured in vitro in semisolid agar with the addition of $20 \%$ fetal bone serum (Sigma, St. Louis, 
MO, USA), 0.33\% bact agar ("Difco", Lawrence, KS, USA), 50 ng/mL GM-CSF (Sigma, USA), and antibiotics (50 IU / $\mathrm{mL}$ penicillin, $50 \mathrm{mg} / \mathrm{mL}$ streptomycin). Cultivation lasted for 14 days at $37{ }^{\circ} \mathrm{C}$ under conditions of near absolute humidity and $5 \% \mathrm{CO}_{2}$. After the end of the cultivation, the numbers of colonies and clusters were counted under an inverted microscope (Nikon, Tokyo, Japan). For cluster identification, a cell aggregate was taken, which included not more than 39 cells. A typical colony (colony-forming unit-granulocyte/macrophage-CFU-GM) included 40 to several hundred cells.

\subsubsection{Histology of Organ Tissues}

Organ tissues were carefully isolated for histological examination and fixed in $4 \%$ neutral buffered formalin. Fixed tissues were dehydrated and embedded in paraffin and then cut into serial $4 \mu \mathrm{m}$ thick sections. The histopathological characteristics were obtained on tissue sections after hematoxylin \& eosin staining in 18 rats ( 3 rats from each group) on the 1 st and 9 th days after Ir.

\subsubsection{EPR Spin-Trapping Detection of Superoxide Ion- $\left[\mathrm{O}_{2} \bullet-\bar{*}\right]$}

$0.5 \mathrm{~g}$ of tissue (lateral part of left liver lobe or right cerebral hemisphere of brain) was dissected, snap frozen in liquid nitrogen, in special home-made press-form (for air bubble evacuation) designed and constructed by IEPOR and then was stored in liquid nitrogen container at $-196{ }^{\circ} \mathrm{C}$ until spectroscopic analysis. The rate of superoxide generation in homogenate of tissue was determined by electron paramagnetic resonance (EPR) in a special paramagnetic pure quartz cuvette after adding to homogenate a spin trap-TEMPONEH (1-hydroxy-2,2,6,6-tetramethyl-4-oxo-piperidine), CAS 3637-11-4, Enzo. EPR spectra from the samples were recorded on a computerized spectrometer PE-1307 with resonator $\mathrm{H} 011$. The power of the microwave source $=40 \mathrm{~mW}$, the modulation frequency $=100 \mathrm{kHz}$, amplitude $=10$ Gauss, and the receiver's constant time $\tau=0.3 \mathrm{~s}$. Rate of $\mathrm{O}_{2}{ }^{\bullet-}$ [15] generation in tissue ( $\mathrm{nmol}$ in $1 \mathrm{~g}$ of tissue during $1 \mathrm{~min}$ ) is linear during $5 \mathrm{~min}$ and every $100 \mathrm{~s}$ EPR spectra were consecutively unregistered and used for calculation

\subsection{Statistical Analysis}

Mean values and standard deviations were calculated. Differences between groups were evaluated statistically with Student's t-test for independent samples, using Microsoft Excel. Group differences were considered significant when $p<0.05$. For CFU statistical analysis of the results was carried out using Mann-Whitney nonparametric comparison. Statistical significance was set at $<0.05$.

\section{Results}

Textural parameters of the synthesized activated carbon were determined using nitrogen adsorption at cryogenic temperatures. As observed in Figure 1, the synthesized sample had a widely developed porous structure with a significant proportion of micropores (above $500 \mathrm{~cm}^{3} / \mathrm{g}$ ) and small mesopores (pore size distribution is reported in Figure $1 \mathrm{~b}$ ). Total pore volume achieved at $\mathrm{p} / \mathrm{p}_{0} \approx 0.98$ was larger than $2250 \mathrm{~cm}^{3} \mathrm{STP} / \mathrm{g}$ (STP-standard pressure and temperatures conditions). This extremely large volume anticipates the exceptional properties of the synthesized sample. The apparent surface area after application of the BET equation was as large as $2700 \mathrm{~m}^{2} / \mathrm{g}$. Micropore volume was only $0.88 \mathrm{~cm}^{3} / \mathrm{g}$, while the total volume at $\mathrm{p} / \mathrm{p}_{0}=0.98$ was around $3.55 \mathrm{~cm}^{3} / \mathrm{g}$. AC had a widely developed porous structure with three main contributions in the narrow micropores $(0.8 \mathrm{~nm})$, wide micropores and narrow mesopores $(3.4 \mathrm{~nm}$ and $4.0 \mathrm{~nm})$ range. 


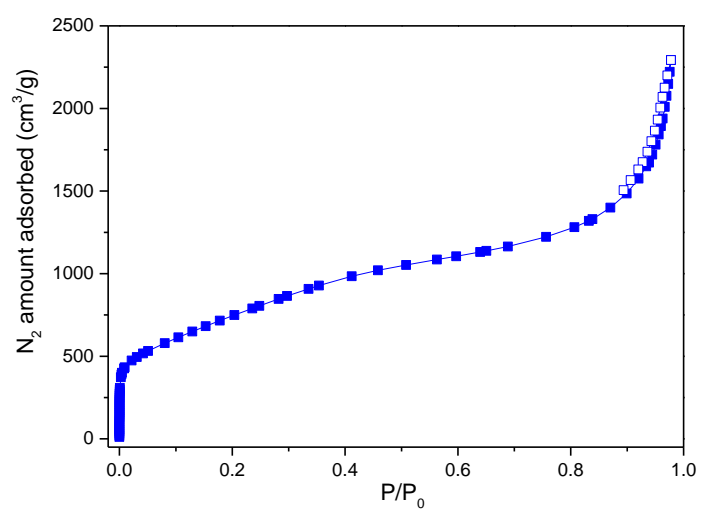

(a)

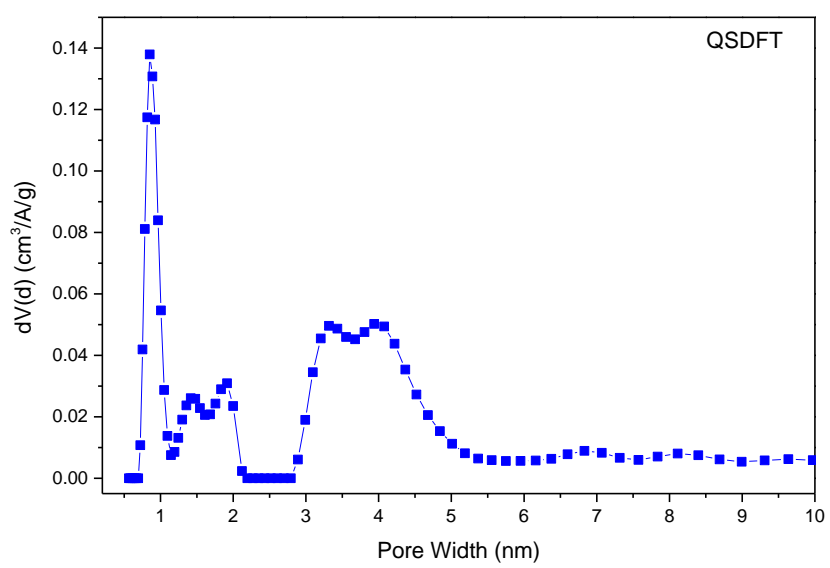

(b)

Figure 1. (a). $\mathrm{N}_{2}$ adsorption (full symbol) and desorption (empty symbol) isotherms at $-196{ }^{\circ} \mathrm{C}$; (b). Pore size distribution obtained after application of the QSDFT method.

Irradiated and healthy control rats were weighed every 2-3 days. As shown in Figure 2, both groups of irradiated animals exhibited severe and rapid body weight loss until 3 days post-irradiation, due to acute radiation syndrome. The body weight loss was less pronounced in the AC treated group. This was followed by a recovery phase for both groups of irradiated rats. Spleens and thymus of both $6 \mathrm{~Gy}$-irradiated and healthy control groups of rats were weighed on days 1 and 9 post-irradiation.

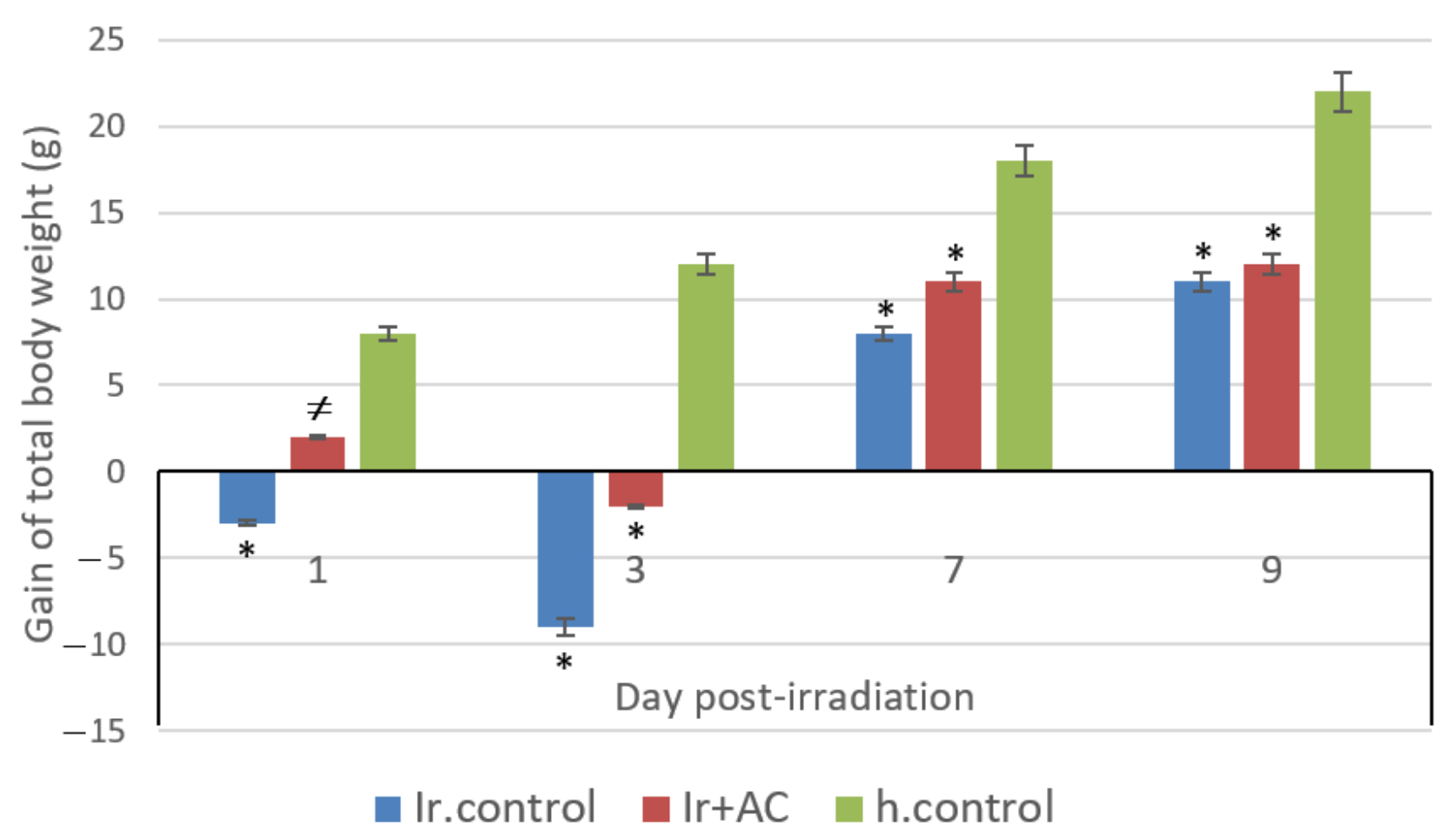

Figure 2. Gain of total body weight by groups of rats, $g$ (delta of weight values in day post and before Irradiation). ${ }^{*} p<0.05$ in comparison with h.control; $\neq p<0.05$ in comparison with Ir.control.

Figure 3 shows that average spleen and thymus weights were strongly decreased on the 1st day after irradiation for both untreated and AC treated rats, when compared to healthy control. Average thymus weights of both irradiated groups were not significantly different from healthy control on the 9 th day after irradiation. Therefore no significant 
differences (except a possible positive tendency of a weight increase in AC treated group) in thymus and spleen recovery were found between Ir control and AC treated groups of rats. The spleen weight of Ir.control and Ir+Ac groups on the 9th day after irradiation was slightly augmented, but less than those in healthy control group.

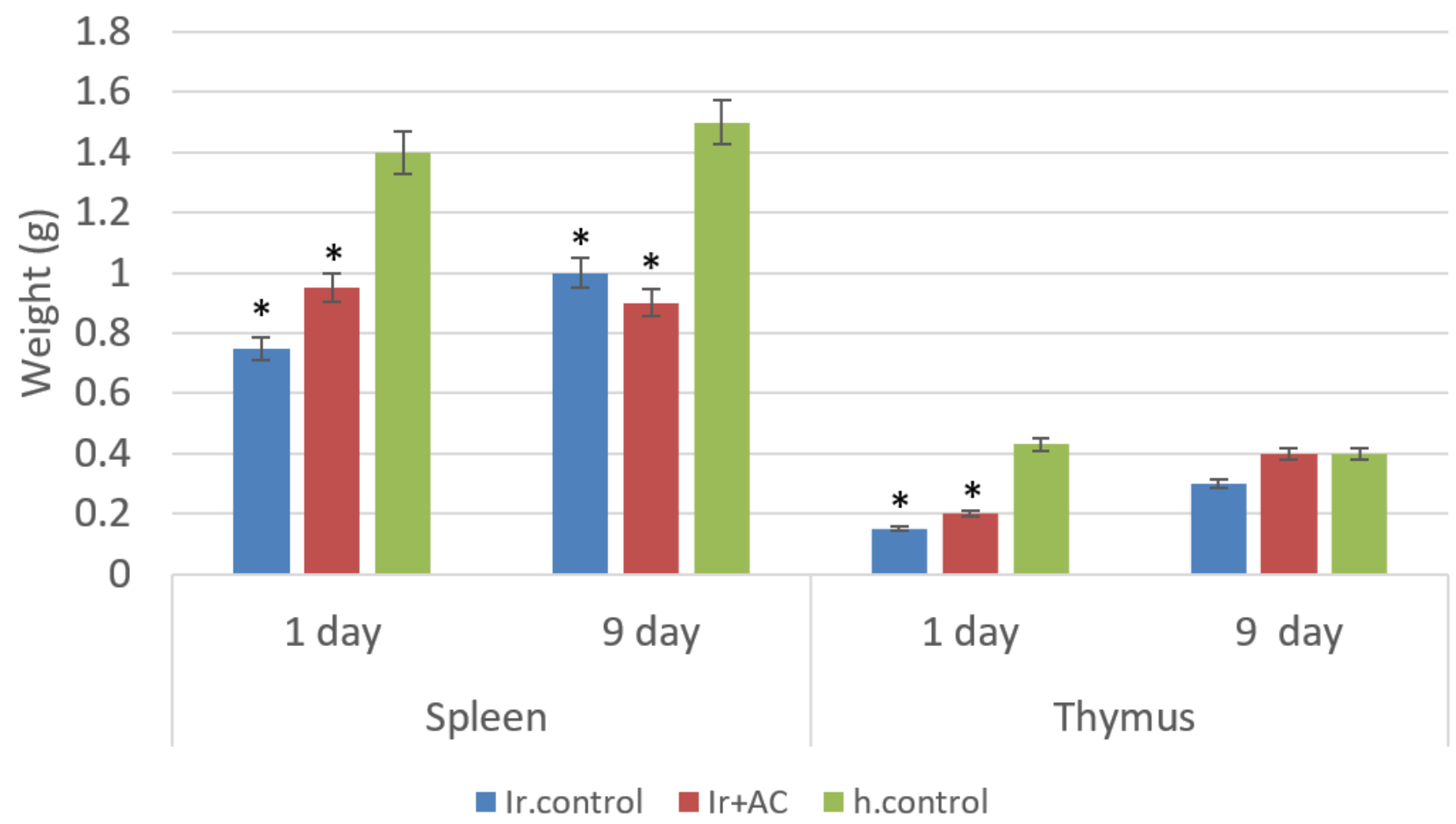

Figure 3. Weight of spleen and thymus of rats on the 1 st and the 9 th post-irradiation day. ${ }^{*} p<0.05$ in comparison with h.control.

Blood cell count (Figure 4) in animals $24 \mathrm{~h}$ after irradiation reveals typical shut down of WBC and lymphocyte levels at 10-12 times less in both irradiated groups versus healthy control. No marked changes in platelet levels were observed in this period after irradiation.

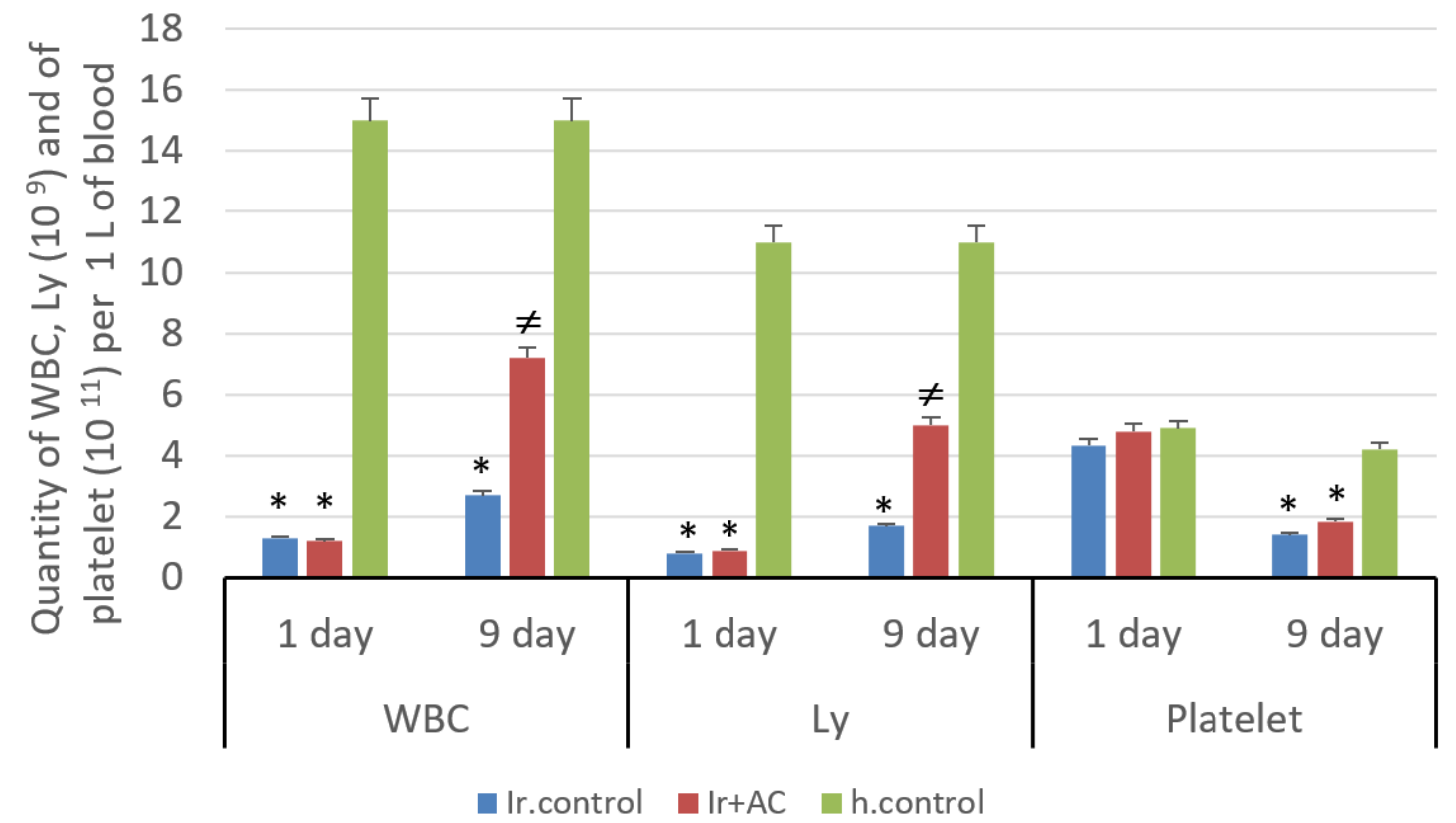

Figure 4. White blood cells (WBC) and lymphocytes (Ly, $\left.10^{9} / \mathrm{L}\right)$; platelets $\left(10^{11} / \mathrm{L}\right)$ in rats on the 1 st and 9 th day after irradiation. ${ }^{*} p<0.05$ in comparison with h.control; $\neq p<0.05$ in comparison with Ir.control. 
On the first day after radiation exposure in both groups bone marrow cells count $\left(10^{6}\right.$ per femur) was $2.4-2.7$ times less $(38.2 \pm 9.4 ; 35.4 \pm 12.0)$ than in healthy controls $(88 \pm 14.7)$. Statistical differences were not found between AC treated and untreated irradiated group during counts $\left(10^{6}\right.$ per femur) of all bone marrow cells and composites: differentiating granulocytes, mature granulocytes, erythroid cells, lymphocytes (Figure 5).

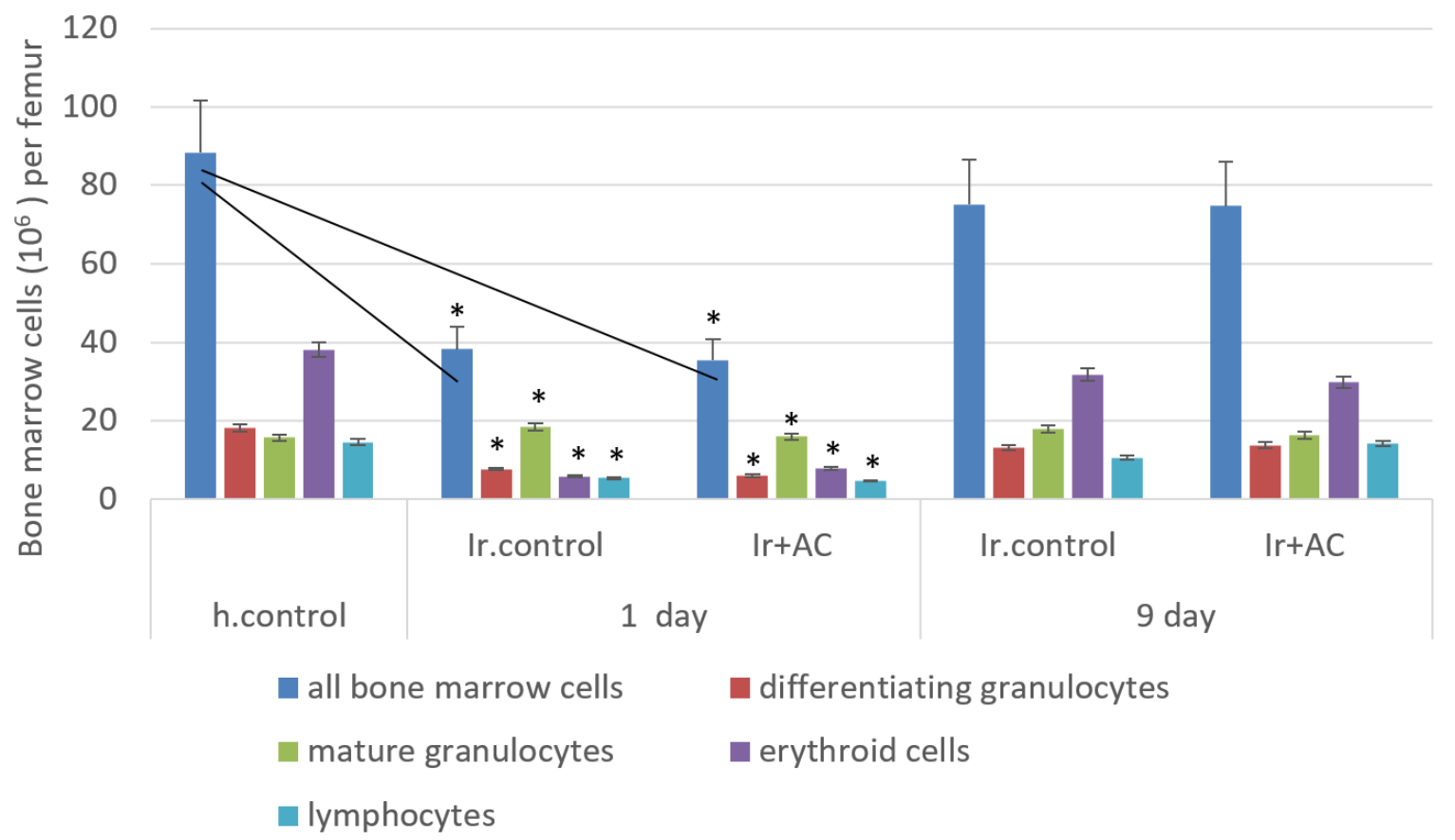

Figure 5. Bone marrow cells $\left(10^{6}\right.$ per femur) in rats on the 1 st and 9 th day after irradiation. ${ }^{*} p<0.05$ in comparison with h.control.

But the results of cultivation of these bone marrow cells, taken $24 \mathrm{~h}$ after animals' irradiation, demonstrate the statistical difference in the efficiency of colony formation, namely, $6 \pm 0.8$ colonies and $5 \pm 1.1$ clusters per $1 \times 10^{5}$ explanted cells in irradiated control group and $9 \pm 1.3$ colonies and $20 \pm 2.4$ clusters per $1 \times 10^{5}$ explanted cells in animals treated with AC before and after irradiation. In both groups Ir.control and $\mathrm{Ir}+\mathrm{AC}$ after radiation exposure, efficiency of colony formation $(6 \pm 0.8$ and $9 \pm 1.3)$ was reduced 3.7 and 2.4 times, respectively, in comparison with healthy control $(22 \pm 1.2)$ per $1 \times 10^{5}$ explanted cells.

On the 9th day after irradiation, enterosorption with $\mathrm{AC}$ in rats contributed to the significant acceleration of WBC and Lymphocyte count restoration in blood of rats (7.2 \pm 0.8 ; $5.0 \pm 0.7)$ in comparison with Ir control group $(2.7 \pm 1.1 ; 1.7 \pm 1.8)$. Platelet levels on the 9th day after irradiation were significantly reduced in both groups with statistical tendency to be higher in AC treated group.

The bone marrow of irradiated animals showed $80-90 \%$ recovery on the 9th post irradiation day (Figure 5) In this period after irradiation, statistical difference is seen between irradiated groups in terms of count of all bone marrow cells $\left(10^{6}\right.$ per femur) and its composites (except mitotic index). The mitotic index of bone marrow cells (Table 1) in AC treated group is statistically higher (13.8) than in the untreated irradiated group (8.8). In the irradiated control group, unlike in AC treated group, the mitotic index of erythroid bone marrow cells (4.2) is less than those of healthy controls. 
Table 1. Mitotic index (quantity of mitosis per 1000 cells): in all bone marrow, erythroid and white bone marrow cells on the 9th day after Irradiation in irradiated control group (Ir.control), irradiated rats receiving activated charcoal (Ir+AC).

\begin{tabular}{cccc}
\hline \multirow{2}{*}{ Groups of Rats } & \multicolumn{3}{c}{ Mitotic Index of Bone Marrow Cells } \\
\cline { 2 - 4 } & All Cells & Erythroid Cells & White Cells \\
\hline Ir control, $(\mathrm{n}=5)$ & $8.8 \pm 1.0$ & $4.2 \pm 1.2 *$ & $4.6 \pm 1.6$ \\
\hline $\mathrm{Ir}+\mathrm{AC},(\mathrm{n}=5)$ & $13.8 \pm 1.5^{* *}$ & $7.0 \pm 1.4$ & $6.8 \pm 0.7$ \\
\hline healthy control, $(\mathrm{n}=5)$ & $11.6 \pm 2.0$ & $6.8 \pm 1.6$ & $4.8 \pm 1.6$ \\
\hline & $* p<0.05$ in comparison with h.control; ${ }^{* *} p<0.01$ in comparison with Ir.control.
\end{tabular}

The results of cytogenetic examination of bone marrow in rats are presented in Table 2. As can be seen, in the cells of healthy control animals the frequency of chromosomal aberrations corresponded to the normal spontaneous level (0-3\%). On the 9th day after irradiation elevated levels of chromosome aberrations in bone marrow cells were observed in all groups of exposed animals. The total frequency of chromosome aberrations in irradiated control animals were more than 2.5 times higher $(4.28 \pm 0.3)$ per 100 metaphases than in healthy controls $(1.6 \pm 0.3)$, and 1.9 times higher than in irradiated groups treated with AC (2.2 \pm 0.2$)$. In the spectrum of chromosomal aberrations of Ir. control group, specific radiation-induced cytogenetic markers, such as dicentric chromosomes and accompanying acentric fragments, were found. In bone marrow of irradiated animals subjected to enterosorption with $\mathrm{AC}$ (Ir+AC group) there were no dicentrics observed on the 9th day of the experiment and the rate of acentric paired fragments was approximately 2.5 times less than in the Ir.control group. As in healthy control, in AC+Ir group the chromatid type aberrations (single chromatid fragments and exchanges) prevailed in the aberration spectrum.

Table 2. Chromosome aberration frequencies in bone marrow cells of rats from the irradiated control group (Ir.control) and irradiated animals receiving activated charcoal $(\mathrm{Ir}+\mathrm{AC})$ on the 9 th day after irradiation.

\begin{tabular}{|c|c|c|c|c|c|c|}
\hline \multirow{3}{*}{ Groups of Rats } & \multirow{3}{*}{$\begin{array}{c}\text { Number of Analyzed } \\
\text { Metaphases }\end{array}$} & \multicolumn{4}{|c|}{ Aberrations per 100 Metaphases } & \multirow[t]{2}{*}{$\begin{array}{c}\text { Total } \\
\text { Aberrations }\end{array}$} \\
\hline & & \multirow{2}{*}{$\begin{array}{l}\text { Chromatid Type } \\
(\mathbf{M} \pm \mathrm{SE})\end{array}$} & \multicolumn{3}{|c|}{ Chromosome Type, $(\mathrm{M} \pm \mathrm{SE})$} & \\
\hline & & & Paired Fragments & Dicentrics & Rings & \\
\hline Ir control, $(\mathrm{n}=5)$ & 755 & $1.9 \pm 0.2$ & $2.3 \pm 0.2$ & $0.1 \pm 0.1$ & 0 & $4.28 \pm 0.3^{*}$ \\
\hline $\mathrm{Ir}+\mathrm{AC},(\mathrm{n}=5)$ & 705 & $1.5 \pm 0.3$ & $0.9 \pm 0.3$ & 0 & 0 & $2.2 \pm 0.2^{* *}$ \\
\hline healthy control, $(\mathrm{n}=5)$ & 740 & $1.2 \pm 0.3$ & $0.3 \pm 0.2$ & 0 & 0 & $1.6 \pm 0.3$ \\
\hline
\end{tabular}

To identify the mechanism underlying the effect of $\mathrm{AC}$, superoxide radical generation rate (SOR) was determined in the brain and liver tissues of rats at days 1 and 9 postirradiation.

As shown in Table 3, in terms of SOR generation rate, there was a 25-fold increase in brain tissue (5.0 \pm 0.4$)$ and (5.1 \pm 0.7$), 5$-fold increase in liver tissue $(1.5 \pm 0.2)$ and $(1.7 \pm 0.2)$ in the Ir.control group when compared with the h.control group $(0.2 \pm 0.1)$ and $(0.3 \pm 0.1)$, respectively at 1 and 9 days post-irradiation. The AC entrosorption pronouncedly decreased the SOR generation rate in the liver (1.7 fold) at days 1 and 9 post-irradiation in comparison with the Ir control group. But in brain in both days after irradiation the high SOR generation rate was not statistical reduced by AC treatment. 
Table 3. SOR generation in liver and brain tissues (nmoL/g per min) of rats on the 1st and 9th day after irradiation in: irradiated control group (Ir.control), irradiated rats receiving activated charcoal (Ir+AC), healthy control group (h.control).

\begin{tabular}{ccccc}
\hline \multirow{2}{*}{ Groups of Rats } & \multicolumn{2}{c}{ Liver } & \multicolumn{2}{c}{ Brain } \\
\cline { 2 - 5 } & 1st Day & 9th Day & 1st Day & 9th Day \\
\hline Ir control, $(\mathrm{n}=5)$ & $1.5 \pm 0.2^{*}$ & $1.7 \pm 0.2^{*}$ & $5.0 \pm 0.4^{*}$ & $5.1 \pm 0.7^{*}$ \\
\hline Ir+AC, $(\mathrm{n}=5)$ & $0.9 \pm 0.2^{* *}$ & $1.0 \pm 0.2^{* *}$ & $4.6 \pm 0.2^{*}$ & $5.2 \pm 0.5^{*}$ \\
\hline healthy control, $(\mathrm{n}=5)$ & $0.3 \pm 0.1$ & $0.2 \pm 0.1$ & $0.2 \pm 0.1$ & $0.3 \pm 0.1$ \\
\hline
\end{tabular}

${ }^{*} p<0.05$ in comparison with h.control; ${ }^{* *} p<0.05$ in comparison with Ir.control.

Macroscopic changes in the small intestine were apparent at 1 day after Irradiation in both Irradiated groups of animals when compared to healthy controls (Figure $6 b, c$ versus Figure $6 \mathrm{a}, \mathrm{a} 1)$. IR-treated animals exhibited severe villous epithelial atrophy, significant loss of crypt architecture, villus degeneration and marked infiltration without any mitosis. These typical signs of severe irradiated damage were detectable at day 9 post-irradiation in the small intestines of irradiated animals (Figure 6c), but not in rats treated with activated carbon (Figure 6e). At day 9 post irradiation, animals treated with AC showed a pronounced level of reduced intestinal morphological changes caused by Ir., including reductions in cellular infiltration and appearance of multiple mitosis.

Aberrant signs of radiation damage in the spleen: the growth of the trabecular and vascular parts, reduction and destruction of lymphoid follicles were prominent in IR control group at the 1st and 9th post-irradiation day (Figure $7 \mathrm{~b}, \mathrm{~d}$ ). The histological picture of the spleen of AC treated animals at 1 day after Irradiation shows the beginning of normalization (Figure $7 \mathrm{a}, \mathrm{c}$ ) and at 9 days post Ir. Significant improvements were seen in: appearance of lymphoid follicles and the restoration of cells number in the subcapsular zone (Figure 7e).

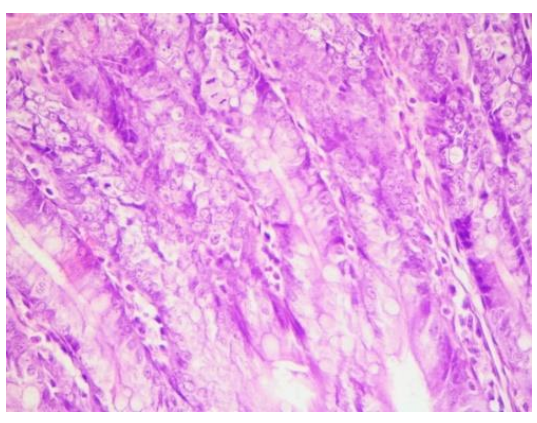

(a)

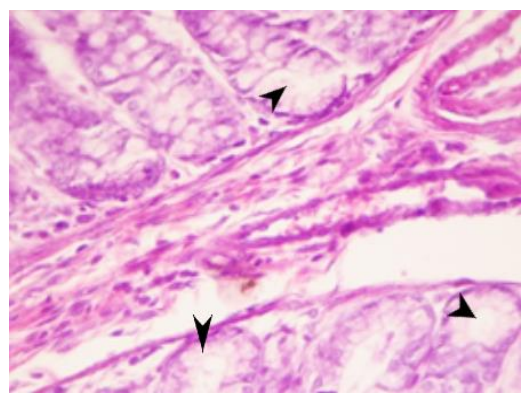

(b)

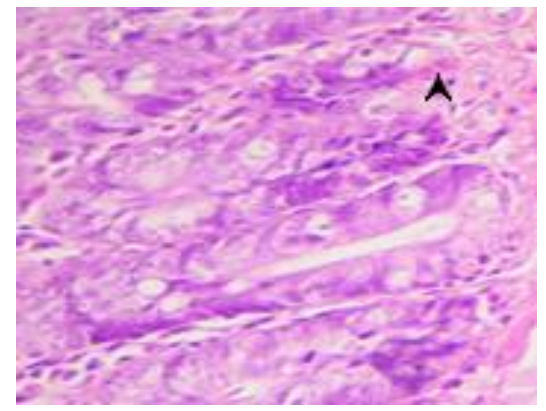

(a1)

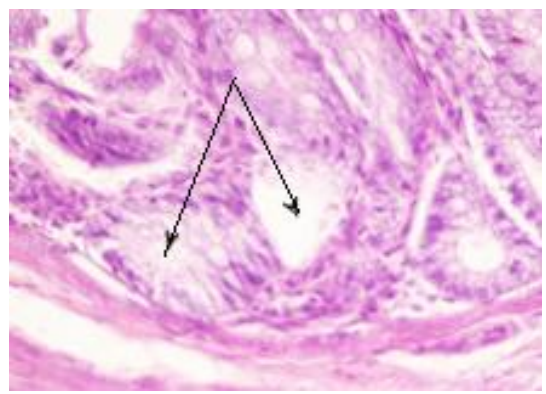

(c)

Figure 6. Cont. 


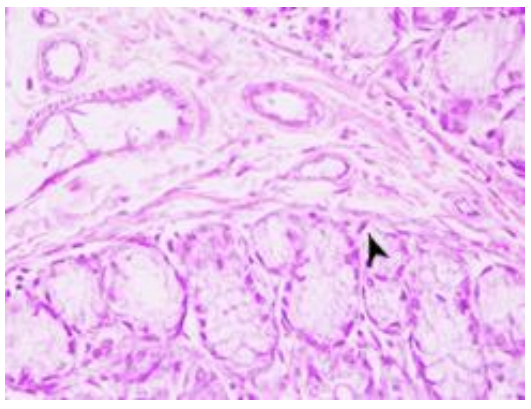

(d)

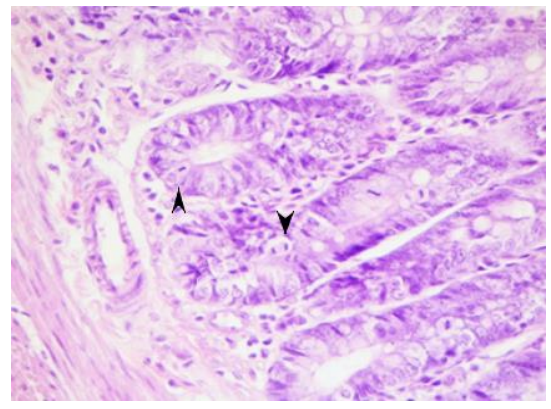

(e)

Figure 6. Effect of activated charcoal (AC) on radiation-induced damage of the small intestine (histological appearance, $\times 400$ magnification). Representative pictures: (a,a1) healthy control group; (a) Cell mitosis in the crypts of the small intestine of healthy animals; (a1) Glandular cells-Paneth cells contain fine-grained acidophilic granules (arrow); (b) Ir. control group (1st day): in most crypts, cells are destroyed and are represented as contours of dead cells (arrows). Only higher to the top of the villi enterocytes have a normal structure. These are differentiated cells, which are less sensitive to the action of radiation, they move to the tops of the villi and desquamate; (c) Ir. control group (9th day) - Crypt cells are not restored; their destruction is observed. Crypts remain empty (arrows), mitotic activity is not observed; (d) Ir+AC group (1st day)—Dystrophic and necrotic changes of enterocytes in the lower part of the villi of the small intestine, the appearance of single mitoses (arrow); (e) Ir+AC group (9th day): The villus enterocytes do not show signs of destruction, have a normal morphology. The appearance of numerous mitoses (arrows).

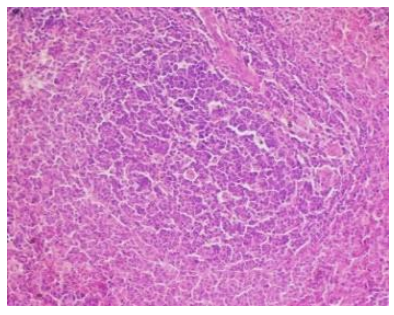

(a)

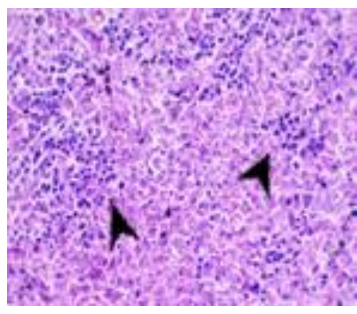

(d)

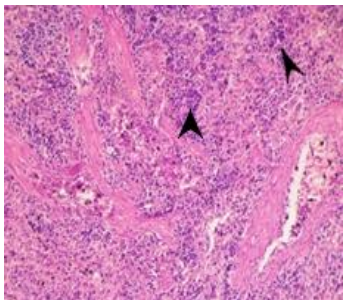

(b)

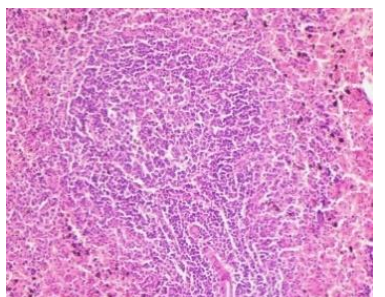

(c)

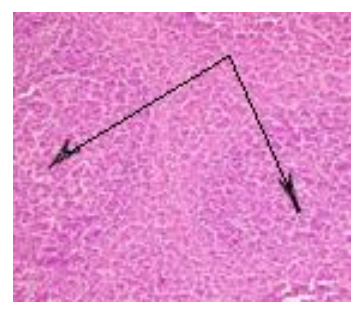

(e)

Figure 7. Effect of activated charcoal (AC) on radiation-induced damage of spleen (histological appearance, $\times 200$ magnification). Representative pictures: (a) healthy control group: lymphoid follicle containing a germinal center in the spleen; (b) Ir. control group: decrease in the size of the lymphoid follicles of the white pulp of the spleen of the animal under the influence of Irradiation (day 1 post-Ir.); (c) Ir + AC group: beginning of normalization of the histological structure of the spleen of the irradiated animal under the influence of AC (day 1 post-Ir); (d) Ir. control group, $\times 400$ magnification (day 9 post-Ir.): the growth of the trabecular and vascular parts of the spleen, the remains of lymphoid follicles, consisting of a small number of cells scattered among the red pulp of the spleen (arrow); (e) Ir+AC group (day 9 post-Ir.): significant improvement in the morphological structure of the spleen towards normalization under the influence of AC. The number of cells in the subcapsular zone increases. Lymphoid follicles of the white pulp appear with formed germinal centers: two lymphoid follicles (arrows) of normal histological structure in the spleen. 


\section{Discussion}

BM suppression is the main symptom of hematopoietic systemic injury seen in the clinic when patients receive traditional cancer therapy, such as chemo- and radiotherapy $[4,16]$. Earlier, we demonstrated that granulated carbon enterosorbent, alone or in combination with filgrastim, possesses the myeloprotective action, which is in direct relation with total specific and mesopore surface areas of activated carbon [4]. The new synthetized activated carbon has exceptional textural properties of combining narrow and wide pores and a large BET surface area- $2700 \mathrm{~m}^{2} / \mathrm{g}$ (a really promising sorbent for gas and liquid process). Study of the functional activity of BM cells taken $24 \mathrm{~h}$ after irradiation in rats treated with AC for 4 days demonstrates that colony and cluster formations by BM cells are 1.5 times and 4 times higher than those in the irradiated control group, despite no statistical differences in the counts of BM and blood cells between irradiated groups. This protection by AC of BM stem cells and later their progenitors, at 9 days post-irradiation, resulted in more than 2 times acceleration of the restoration of blood leucocytes and lymphocytes counts when compared to the untreated irradiated control group (Figure 4). The levels of chromosomal aberrations, such as dicentrics and accompanying pair fragments - typical for ionizing radiation damage were substantially lower on the 9th day after radiation exposure, and only pair fragments (about 2.5 times less than in Ir. control group) were observed. The effect of AC on radiation-induced damage of highly radiosensitive tissues such as the small intestines and spleen were evaluated. AC has only some positive impacts on histopathological characteristics of rat small intestine $24 \mathrm{~h}$ after Irradiation damage. However, at day 9 post-irradiation enterosorption with AC in comparison with Ir.control pronouncedly diminished in the small intestine mucosal atrophy, disruption of muscular layer fibers, villous edema and activated mitosis (Figure 6). Spleen radiation considerably reduced the number of germinal centers, decreased cellularity of immunocompetent cells, and enhanced vascular damage with focal hemorrhage. AC treatment significantly preserved spleen cellularity and germinal centers to almost normal extent at 1- and 9-days post-irradiation (Figure 7). The preservation of spleen histology produced by AC is associated with statistical tendency of spleen wet weight conservation, which was reduced after radiation exposure $24 \mathrm{~h}$ after Ir. (Figure 3). Reactive oxygen species and free radicals generated by the cells induce the formation of oxidized products and contribute to cytotoxicity, fibrosis and inflammation. After irradiation of normal tissues, different events occur including oxidative stress producing the alteration of biological functions. It leads to the chronic inflammatory healing response that leads to parenchymal and vascular cell dysfunction $[17,18]$. In the brain and liver of rats, superoxide ion generation rate was 25 and 5 times higher than in healthy control animals at days 1 and 9 post-Ir, respectively (Table 3 ). Oral use of AC causes an approximately 2 -fold reduction in SOR generation rate after irradiation in the liver but not in the brain. This anti-oxidant property is possibly one of the main key mechanisms by which activated carbon has a positive impact on weight loss, bone marrow functional activity and radiation-induced genotoxicity, leucocyte and lymphocyte levels in blood, histological appearance of the small intestine and spleen in rats after total body irradiation. AC can withdraw from biological fluids different toxic substances [6,7] and contributes to restoration of natural defense of organism. Its combination with stimulators of hematopoietic system (colonystimulating factors) or NPLAT approved for ARS treatment seems to be interesting for further investigation. Refinement of $\mathrm{AC}$ administration conditions and evaluation of $\mathrm{AC}$ impact on survival rate of animals irradiated in lethal doses are underway. In summary, the oral administration of activated carbon is a perspective medical countermeasure to radiation exposure.

Author Contributions: All authors contributed to the study conception and design. Material preparation, data collection and analysis were performed by N.R. (Natalia Rodionova), N.R. (Natalia Riabchenko), E.S., A.S., O.Y., K.B., J.S.-A., D.B., M.P. The first draft of the manuscript was written by E.S. and all authors commented on previous versions of the manuscript. Conceptualization: V.N., M.A., E.S., J.S.-A.; Methodology: M.A., E.S., J.S.-A., N.R. (Natalia Rodionova); Formal analysis and 
investigation: N.R. (Natalia Rodionova), N.R. (Natalia Riabchenko), E.S., A.S., O.Y., K.B., J.S.-A., D.B., M.P.; Writing—original draft preparation: E.S.; Writing—review and editing: V.N., M.A.; Funding acquisition: V.N., M.A., E.S., J.S.-A. Supervision: M.A., V.N., J.S.-A. All authors have read and agreed to the published version of the manuscript.

Funding: This research was funded by H2020-MSCA-RISE-2016 project, grant number 734641 acronym NanoMed.

Institutional Review Board Statement: The study was conducted according to the guidelines of the Declaration of Helsinki, and approved by the IEPOR Ethics Committee, protocol No 4 dated 16 April 2015.

Informed Consent Statement: Not applicable.

Acknowledgments: We thank Nima Davoodi, Burlaka AP, Pyatchanina TV, Mazur MG, Levchenko KA, Shevchuk O.O. for assistance and useful discussion.

Conflicts of Interest: The authors declare no conflict of interest.

\section{References}

1. Bunin, D.I.; Bakke, J.; Green, C.E.; Javitz, H.S.; Fielden, M.; Chang, P.Y. Romiplostim (Nplate ${ }^{\circledR}$ ) as an effective radiation countermeasure to improve survival and platelet recovery in mice. Int. J. Radiat. Biol. 2020, 96, 145-154. [CrossRef] [PubMed]

2. Kashiwakura, I. Overview of Radiation-protective Agent Research and Prospects for the Future. Jpn. J. Health Phys. 2017, 52, 285-295. [CrossRef]

3. Nikolaev, V.; Pinchuk, L.; Umansky, M.; Pinchuk, V.; Burushkina, T.; Petrenko, S.; Rodionova, N.; Snezhkoua, E.; Bichkoua, N. Early Experimental Studies on Hemoperfusion as a Treatment Modality for Acute Radiation Disease. Artif. Organs 1993, 17, 362-365. [CrossRef] [PubMed]

4. Shevchuk, O.O.; Snezhkova, E.A.; Bardakhivskaya, K.I.; Nikolaev, V.G. Adsorptive treatment of acute radiation sickness: Past achievements and new prospects in Hemoperfusion, Plasmaperfusion and other Clinical Uses of General, Biospecific, Immuno and Leucocyte Adsorbents. In Regenerative Medicine, Artificial Cells and Nanomedicine; Chang, T.M.S., Endo, Y., Nikolaev, V.G., Tani, T., Yu, Y., Zheng, W.-H., Eds.; World Scientific Publishing: Hackensack, NJ, USA, 2017; Volume 4, pp. 245-256. [CrossRef]

5. Zakharash, M.P.; Ivanova, N.V.; Maslenny, V.N.; Sakhno, L.A.; Sklyarenko, V.G.; Shmatko, I.I.; Snezhkova, E.A.; Bardakhivskaya, K.I.; Sarnatskaya, V.V.; Nikolaev, V.G. Progress and prospects of adsorption therapy in the treatment of postradiation neurosomatic polypathia. Int. J. Radiat. Med. 2003, 5, 256-262.

6. Pavlenko, D.; Giasafaki, D.; Charalambopoulou, G.; Van Geffen, E.; Gerritsen, K.G.F.; Steriotis, T.; Stamatialis, D. Carbon Adsorbents With Dual Porosity for Efficient Removal of Uremic Toxins and Cytokines from Human Plasma. Sci. Rep. 2017, 7, 14914. [CrossRef] [PubMed]

7. Sarnatskaya, V.; Mikhailenko, V.; Prokopenko, I.; Gerashchenko, B.I.; Shevchuk, O.; Yushko, L.; Glavin, A.; Makovetska, L.; Sakhno, L.; Sydorenko, O.; et al. The effect of two formulations of carbon enterosorbents on oxidative stress indexes and molecular conformation of serum albumin in experimental animals exposed to CCl4. Heliyon 2020, 6, e03126. [CrossRef] [PubMed]

8. Hall, S.; Rudrawar, S.; Zunk, M.; Bernaitis, N.; Arora, D.; McDermott, C.M.; Anoopkumar-Dukie, S. Protection against Radiotherapy-Induced Toxicity. Antioxidants 2016, 5, 22. [CrossRef]

9. Kiang, J.G.; Olabisi, A.O. Radiation: A poly-traumatic hit leading to multi-organ injury. Cell Biosci. 2019, 1-15. [CrossRef] [PubMed]

10. MacNaughton, W.K. Review article: New insights into the pathologenesis of radiation-induced intestinal dysfunction. Aliment. Pharmacol. Ther. 2000, 14, 523-528. [CrossRef] [PubMed]

11. Kiang, J.G. Adult Mesenchymal Stem Cells and Radiation Injury. Health Phys. 2016, 111, 198-203. [CrossRef] [PubMed]

12. Dainiak, N. Hematologic consequences of exposure to ionizing radiation. Exp. Hematol. 2002, 30, 513-528. [CrossRef]

13. Thommes, M.; Kaneko, K.; Neimark, A.V.; Olivier, J.P.; Rodriguez-Reinoso, F.; Rouquerol, J.; Sing, K.S. Physisorption of gases, with special reference to the evaluation of surface area and pore size distribution (IUPAC Technical Report). Pure Appl. Chem. 2015, 87, 1051-1069. [CrossRef]

14. OECD. Test No. 475: Mammalian Bone Marrow Chromosomal Aberration Test; OECD Publishing: Paris, France, 2016. [CrossRef]

15. Babić, N.; Peyrot, F. Molecular Probes for Evaluation of Oxidative Stress by In Vivo EPR Spectroscopy and Imaging: State-of-theArt and Limitations. Magnetochemistry 2019, 5, 13. [CrossRef]

16. Acharya, S.S.; Fendler, W.; Watson, J.; Hamilton, A.; Dipanjan, C.; Gaudiano, E.; Moskwa, P.; Bhanja, P.; Saha, S.; Guha, C.; et al. Serum microRNAs are early indicators of survival after radiation-induced hematopoietic injury. Sci. Transl. Med. 2015, 7, 287ra69. [CrossRef] [PubMed]

17. Zhao, W.; Diz, D.I.; Robbins, M.E. Oxidative damage pathways in relation to normal tissue injury. Br. J. Radiol. 2007, 80, S23-S31. [CrossRef] [PubMed]

18. Wei, J.; Wang, B.; Wang, H.; Meng, L.; Zhao, Q.; Li, X.; Xin, Y.; Jiang, X. Radiation-Induced Normal Tissue Damage: Oxidative Stress and Epigenetic Mechanisms. Oxid. Med. Cell. Longev. 2019, 3010342. [CrossRef] [PubMed] 